\title{
Petrology Characters of Conglomerates in Baikouquan Formation, Mahu Sag, Junggar Basin
}

\author{
Huimin Zhang, Xiangliang Lin, Chao Wang \\ School of Information and Mathematics, Yangtze University, Jingzhou, China \\ Email: 18986706191@163.com
}

How to cite this paper: Zhang, H. M., Lin, X. L., \& Wang, C. (2019). Petrology Characters of Conglomerates in Baikouquan Formation, Mahu Sag, Junggar Basin. Journal of Geoscience and Environment Protection, 7,214-222.

https://doi.org/10.4236/gep.2019.74014

Received: March 25, 2019

Accepted: April 25, 2019

Published: April 28, 2019

Copyright $\odot 2019$ by author(s) and Scientific Research Publishing Inc. This work is licensed under the Creative Commons Attribution International License (CC BY 4.0).

http://creativecommons.org/licenses/by/4.0/

\begin{abstract}
Mahu Sag, one of the most oil and gas bearing sags in Junggar basin, is in the northwestern margin of the basin. On gentle slope region of the sag, a serial of large scale coarse fan delta deposits were developed in Triassic Baikouquan Formation. In order to understand the petrology characters of conglomerates in Baikouquan Formation, based on lots of cores, grain size analysis, normal thin sections, casting thin sections, scanning electron photomicrographs, mineral composition identifications, clay mineral and bulk composition identifications of X-ray diffraction, were comparatively studied for Xiazijie and Huangyangquan fan-delta in Mahu Sag. Mineral composition of conglomerates is main tuff, while eurite, dacite, rhyolite, andesite and granite are common. However, more tuff and granite, less eurite and andesite in Xiazijie fan-delta, there is no rhyolite in Huangyangquan fan-delta. Kaolinization and chloritization of conglomerates are ubiquitous in the formation. The content of chlorite and kaolinite is higher in Xiazijie fan-delta, with lower illite-smectite and illite. There is less feldspar of clastic and more calcite of cement in Xiazijie fan-delta.
\end{abstract}

\section{Keywords}

Mahu Sag, Conglomerates, Mineral Composition

\section{Introduction}

The Mahu Depression is one of the six major hydrocarbon-bearing foreland sags located at the northwestern margin of Junggar Basin, China (Tang et al., 2014). The large coarse-grained proximal fan-delta depositional systems developed in the Triassic Baikouquan Formation under the gentle slope background (Yu et 
al., 2014). In recent years, major breakthroughs have been made in oil and gas exploration in the slope of Mahu Depression (Zhang et al., 2015a). Some large tight lithologic reservoirs (Lei et al., 2014) have been found in the sandy conglomerate in the fan delta front. However, there is little published literature on petrological characteristics of reservoirs, most of which are lacking in comprehensiveness and systematicness (Tan et al., 2014). Therefore, this paper focuses on a large number of laboratory data of drilling coring and various rock analyses, and takes Xiazijie fan-delta and Huangyangquan fan-delta as examples. On this basis, this paper further makes a comparative analysis and research from macro to micro on the petrological characteristics of glutenite reservoirs of Baikouquan Formation in Mahu Depression. On the basis of the data of rock particle size analysis, mineral composition identification, X-ray diffraction of clay mineral composition and whole rock analysis, this paper combines the observation of ordinary slice, cast slice and scanning electron microscope observation to carry out relevant summary on the characteristics of various rock mineral contents of the two fan-delta bodies.

\section{Geological Background}

During the Late Paleozoic, the Junggar-Turpan Plate subducted and collided with the Kazakhstan Plate, and the folded mountain system in West Junggar was strongly uplifted and thrust towards Junggar Block (He et al., 2004). This makes the northwestern margin of Junggar a large foreland basin. Mahu depression is located in the front facies belt of the foreland basin (Kuang \& Qi, 2006). On the hanging wall of thrust fault, Zaire and Hala'alatmountains' carboniferous and the firestone in the Permian Jiamuhe Formation were supplied sufficient material sources for Mahu Depression during the Early Triassic (Qu et al., 2015). One part of these coarse sediments accumulated at the margin of depression by the interaction of gravity formed alluvial fans, while others moved further to the center of the basin and enter into the shallow water of Mahu Depression, resulting in a series of proximal fan-delta aprons in the gentle slope zone (Kuang et al., 2014). This paper takes Xiazijie fan-delta and Huangyangquan fan-delta as research objects (See Figure 1). From bottom to top, the Triassic strata can be divided into three members, marked as T1b (Baikouquan Formation), T2k (Karamay Formation) and T3b (Baijiantan Formation), and the thickness of the Baikouquan Formation as the target strata, is 120 - $250 \mathrm{~m}$, are mainly grayish green, gray, red-dark brown glutenite and red-dark brown mudstone interbeds.

\section{Characteristics of Glutenite Minerals}

According to the identification of mineral composition, the mineral composition of the glutenite reservoir of Baikouquan Formation can be mainly divided into 4 categories, including the gravelly and sandy and matrix as well as cements.

The gravelly mineral composition of Xiazijie fan-delta is mainly tuff, followed by felsite, dacite, rhyolite, andesite, granite and so on, with a small amount of 


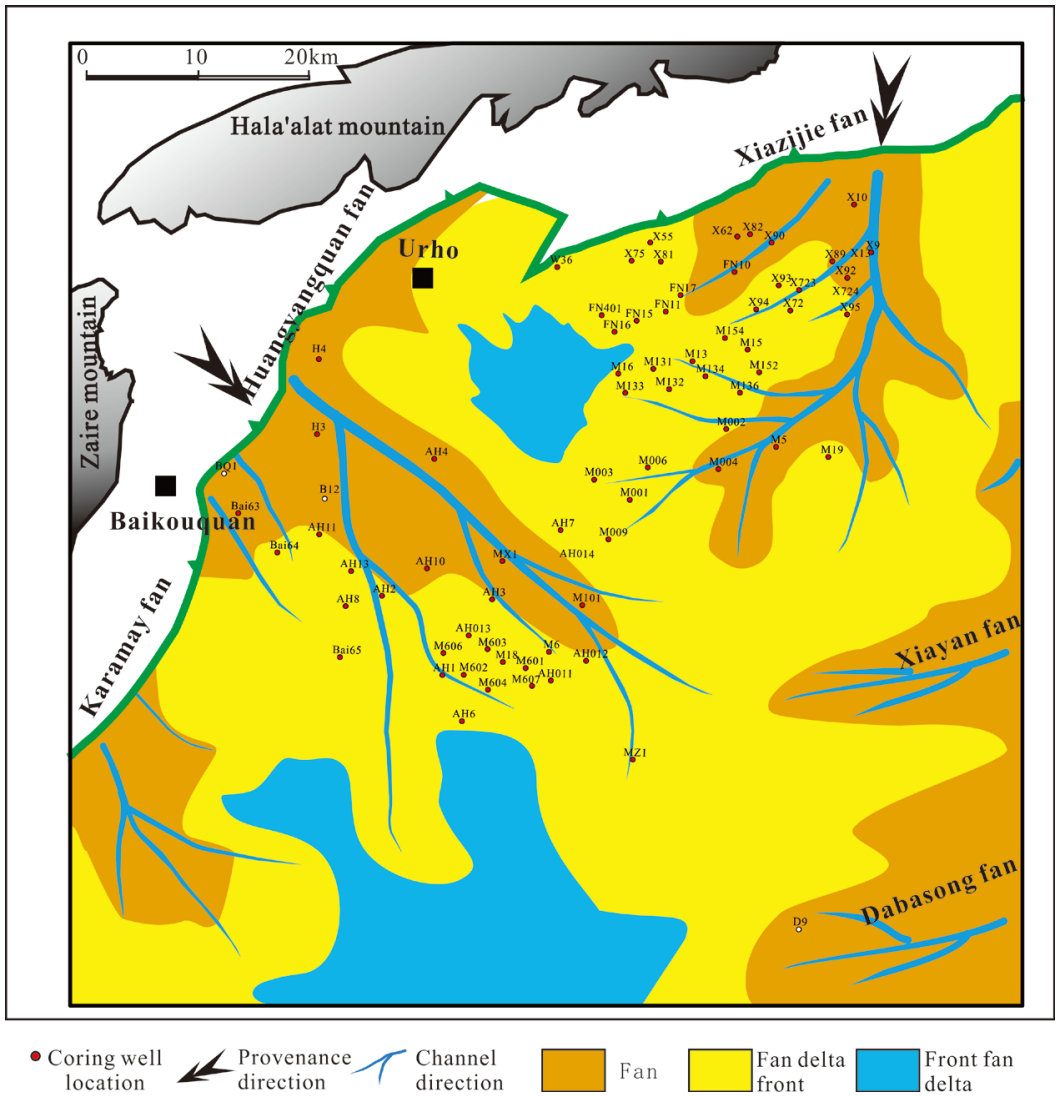

Figure 1. Sedimentary facies plan and stratigraphic features of the study area (according to Xinjiang Oilfield Company).

sedimentary rocks (e.g. sandy and argillaceous). Also, the main gravelly mineral composition of Huangyangquan fan delta is the tuff and the sedimentary rocks (e.g. argillaceous and sandy) of it are relatively high, followed by granite and felsite, with a small amount of argillaceous slate and andesite. The average content of gravelly tuff, sedimentary rock and granite in Huangyangquan fan-delta is higher than that in Xiazijie fan-delta, while the average content of felsite and andesite is lower than that in Xiazijie fan-delta, with almost excluding rhyolite. The statistical results of percentage content of gravelly mineral composition mass of glutenite in Xiazijie fan-delta and Huangyangquan fan-delta are shown in Figure 2(a) and Figure 2(b). (Only the minerals with frequency greater than $2 \%$ in the analysis results are shown.)

The sandy mineral composition of Xiazijie fan-delta is mainly tuff, which generally contains sedimentary rocks (e.g. sandy, argillaceous and siliceous) and felsite, granite and andesite. The sandy mineral composition of Huangyangquan fan-delta is similar to that of Xiazijie fan-delta. However, the average content of granite is larger than that of Xiazijie fan-delta, while the average content of felsite and andesite is smaller than that of Xiazijie fan-delta. The statistical results of sand mineral composition mass percentage of glutenite in Xiazijie fan-delta and Huangyangquan fan-delta are shown in Figure 3(a) and Figure 3(b). (Only the minerals with frequency greater than $2 \%$ in the analysis results are shown.) 


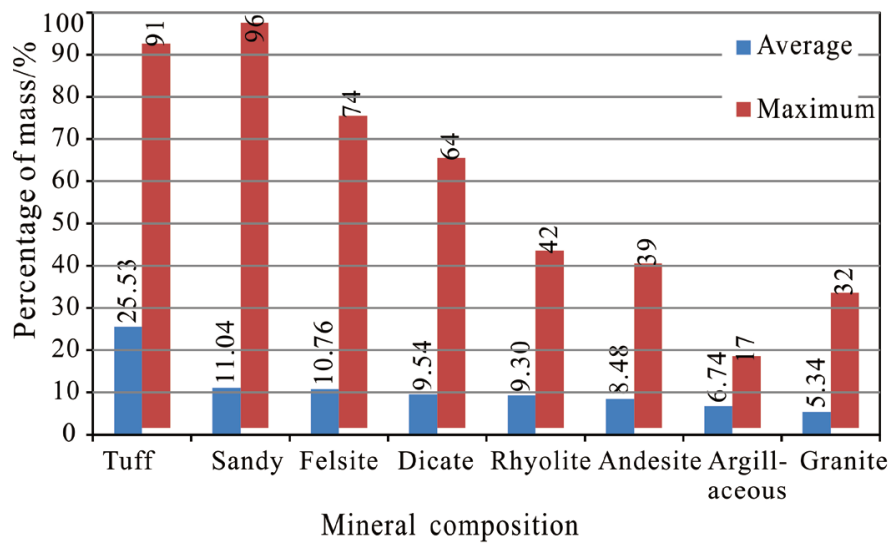

(a)

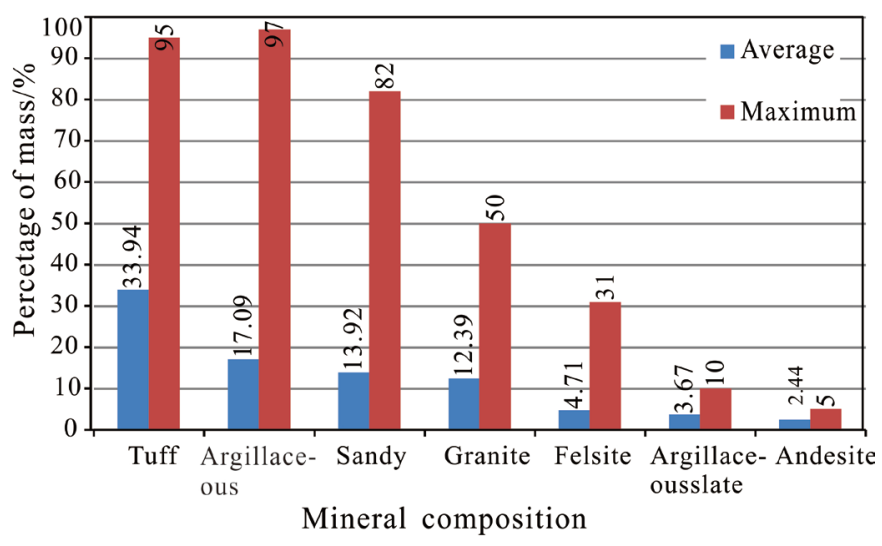

(b)

Figure 2. Percentage content of gravelly mineral composition mass of glutenite in Xiazijie fan-delta and Huangyangquan fan-delta. (a) Xiazijie fan (16 wells, 1394 analysis results); (b) Huangyangquan fan (12 wells, 383 analysis results).

The mineral composition of the glutenite of Baikouquan Formation in the Mahu Depression generally contains slightly acidic volcanic rocks. Among them, the average content of the delta tuff and granite of Huangyangquan fan-delta is larger than that of Xiazijie fan-delta, while the average content of the tuff and andesite of Huangyangquan fan-delta is smaller than that of Xiazijie fan-delta. In addition, the average content of rhyolite in Xiazijie fan-delta is higher, while it is difficult to develop in Huangyangquan fan-delta.

As the interstitial materials, the composition and content of matrix and cements are similar in the glutenite reservoir of each sector of Baikouquan Formation in the study area. Specifically, the matrix is mainly argillaceous (including a small amount of chloritization argillaceous, hydrobiotite argillaceous and hydromica argillaceous), with an average of $2.5 \%$ and a maximum of $12 \%$, and Kaolinite and chlorite are few, as well as a small amount of hydrobiotite, hydromica and iron-stained argillaceous are developed. Cements are mainly calcite, with an average of $3.6 \%$ and a maximum of $15 \%$ and containing a small amount of analcite, siliceous and ankerite (Figure 4). 


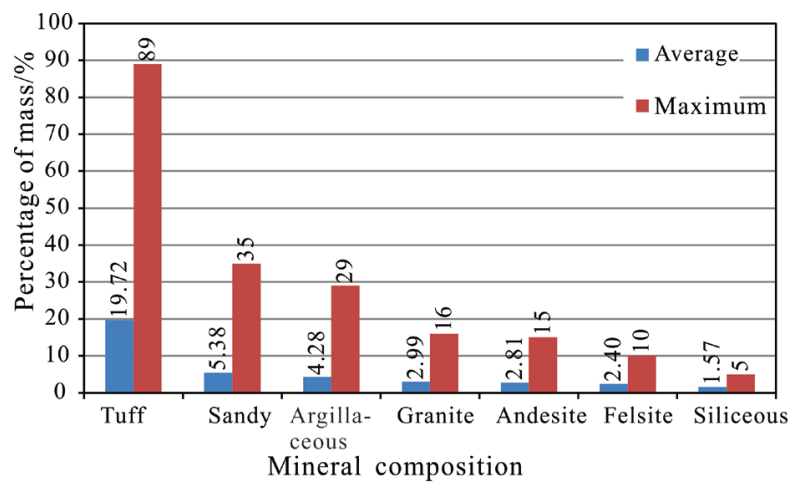

(a)

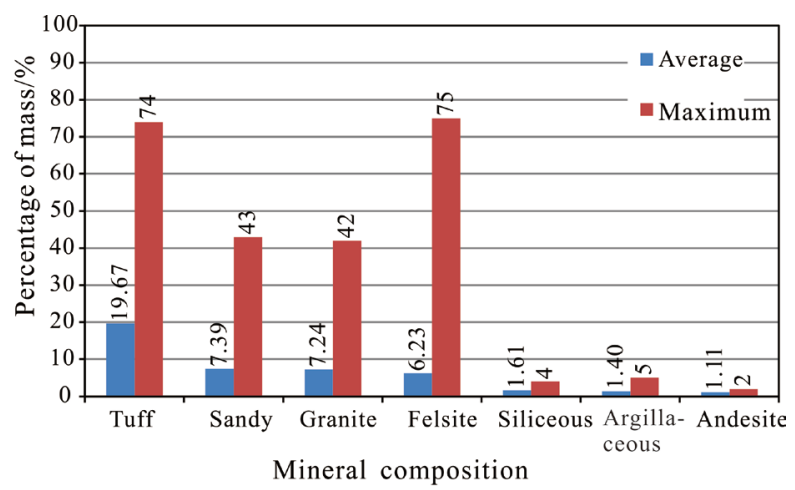

(b)

Figure 3. Sand mineral composition mass percentage of glutenite in Xiazijie fan-delta and Huangyangquan fan-delta. (a) Xiazijie fan (16 wells, 1662 analysis results); (b) Huangyangquan fan (12 wells, 653 analysis results).

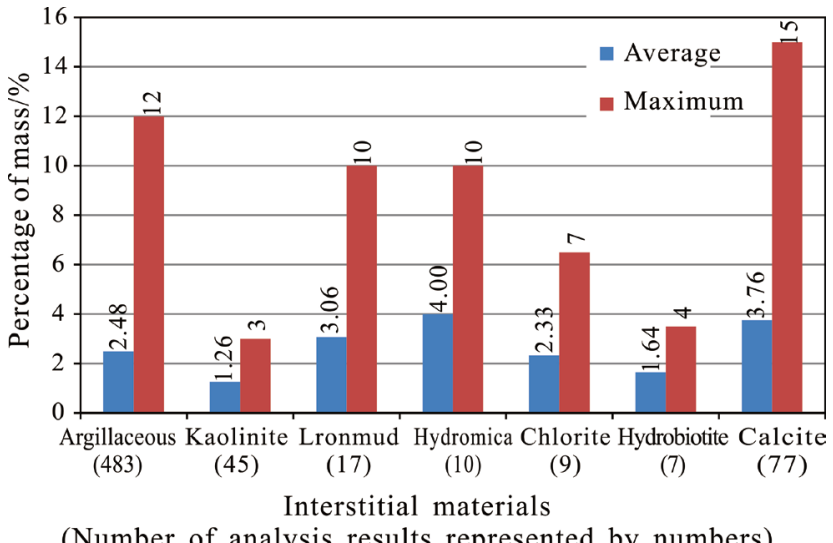

Figure 4. Percentage content of interstitial materials mass of glutenite reservoir of Baikouquan Formation.

\section{Characteristics of Clay Minerals}

Generally, the clay minerals in the glutenite reservoir of Baikouquan Formation in Mahu Depression mainly include 4 types, including the Imon mixed layer, illite, kaolinite and chlorite (Zhi, 2016). Due to the dense glutenite reservoir of the Baikouquan Formation has the phenomenon of kaolinite and chlorite, the con- 
tent of the two are higher in the clay minerals (Liu et al., 2016). Between them, the authigenic chlorite is essentially in the form of a membranous cement, forming an almost equal thick annular edge on the surface of the particle, which has a positive effect on dense reservoirs and develops relatively high-quality reservoirs (Cao et al., 2005). Kaolinite is a sheet-like (or book-like) or worm-like shape that is usually filled between particles and is a product of aqueous acidic fluids and alkaline feldspars in sandstone (Zhang et al., 2015b).

It is worth noting that the clay minerals in Xiazijie fan-delta are mainly Imon mixed layer, chlorite and kaolinite, with lessillite. The clay minerals in Huangyangquan fan-delta are mainly Imon mixed layer, followed by chlorite, while kaolinite and illite are undeveloped. Therefore, the average content of Imon mixed layer and illite in clay minerals in Xiazijie fan-delta is lower than that in Huangyangquan fan-delta, while the average content of chlorite and kaolinite is higher than that in Huangyangquan fan-delta. The chloritization and kaolinization of Xiazijie fan-delta are relatively strong. The statistical results of percentage content of X-ray diffraction clay mineral composition mass of 277 samples collected from 29 wells in the study area are shown in Figure 5(a) and Figure 5(b).

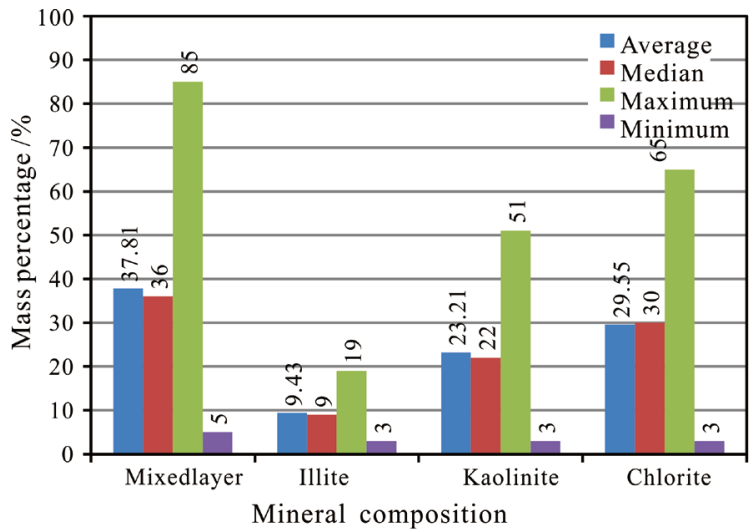

(a)

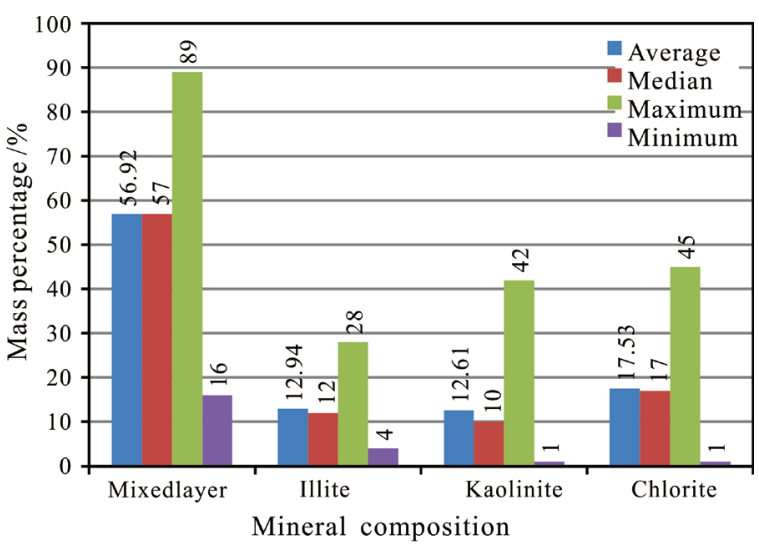

(b)

Figure 5. Clay mineral composition mass percentage in Xiazijie fan-delta and Huangyangquan fan-delta. (a) Xiazijie fan (16 wells, 146 samples); (b) Huangyangquan fan (13 wells, 131 samples). 


\section{Characteristics of Total Rock}

The mineral debris of glutenite of Baikouquan Formation in Mahu Depression is mainly the quartz and feldspar which includes the plagioclase and potash feldspar, and the cement is mainly the calcite with containing a small amount of ankerite. Based on this, it is undeniable that the Xiazijie fan-delta and Huangyangquan fan-delta show some differences in the whole rock analysis results. Specifically, the feldspar content in Xiazijie fan-delta is generally less than $50 \%$, while calcite content is generally less than $5 \%$. However, feldspar content in Huangyangquan fan-delta is generally more than $50 \%$, while calcite content varies from $5 \%$ to $35 \%$. Additionally, the X-ray diffraction triangle of the whole rock analysis of 221 samples collected from 23 wells in the study area is shown in Figure 6.

In summary, according to the average content and the maximum content of each component, it is apparent that the quartz contents in the two fans are close to each other. However, the average content of feldspar in Xiazijie fan-delta is smaller than that in Huangyangquan fan-delta, while the average content of calcite in Xiazijie fan-delta is larger than that in Huangyangquan fan-delta, and ankerite cement is not detected in Huangyangquan fan-delta. The statistical results of the percentage content of the component mass of the X-ray diffraction whole rock analysis are shown in Figure 7(a) and Figure 7(b).

\section{Conclusion}

The main mineral composition of conglomerate is the tuff, with generally containing felsite, dacite, rhyolite, andesite, granite and so on. Among them, the average content of tuff and granite in Xiazijie fan-delta is smaller than that in Huangyangquan fan-delta; the average content of felsite and andesite in Xiazijie fan-delta is larger than that in Huangyangquan fan-delta. And the rhyolite has a high average content in Xiazijie fan-delta, while it hardly develops in Huangyangquan fan-delta.

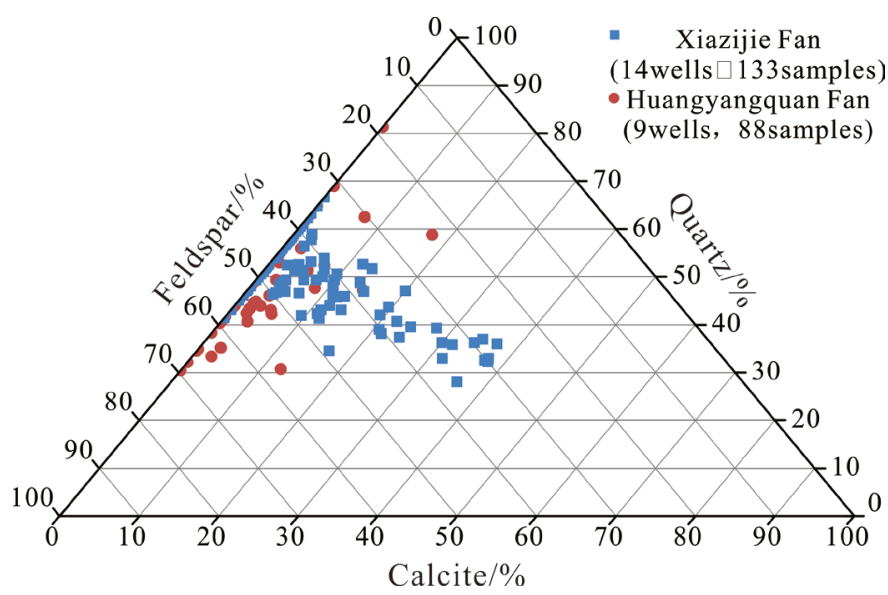

Figure 6. Triangular diagram of the whole rock glutenite composition of Xiazijie fan-delta and Huangyangquan fan-delta. 


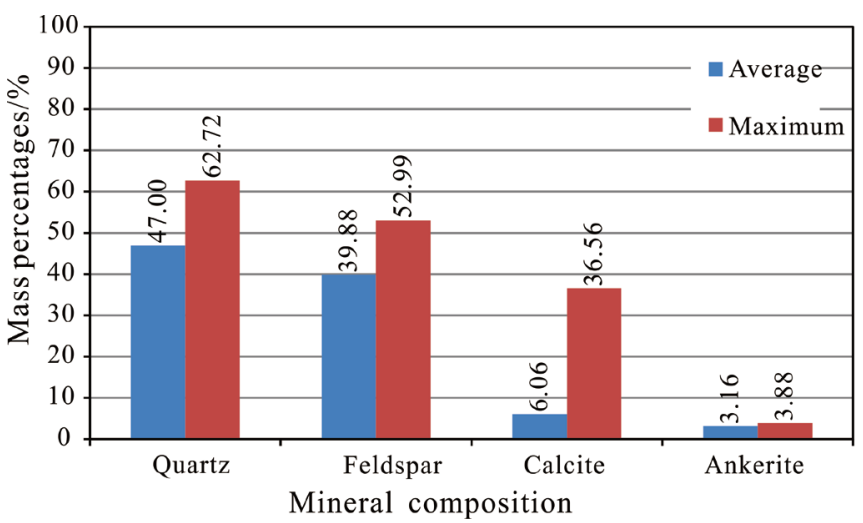

(a)

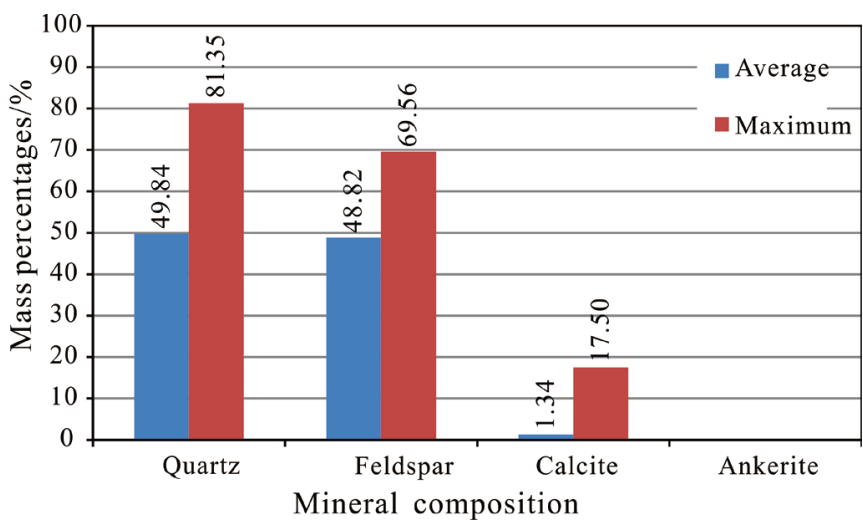

(b)

Figure 7. Quantity percentage of whole rock glutenite mass in Xiazijie fan-delta and Huangyangquan fan-delta. (a) Xiazijie fan (14 wells, 133 samples); (b) Huangyangquan fan (9 wells, 88 samples).

Kaolin and chlorination in glutenite reservoirs are very common, and the content of kaolinite and chlorite in clay minerals is relatively high. The average content of chlorite and kaolinite in Xiazijie fan-delta is larger than that in Huangyangquan fan-delta, while the average content of illite and imon mixed layer in Xiazijie fan-delta is smaller than that in Huangyangquan fan delta. The average content of mineral clastic feldspar in Xiazijie fan-delta is less than that in Huangyangquan fan delta, while the average content of cement calcite in Xiazijie fan delta is larger than that in Huangyangquan fan-delta.

\section{Acknowledgements}

This research is financially supported by Scientific Research Project of Hubei Provincial Department of Education (No. Q20181310). The supports are gratefully acknowledged.

\section{Conflicts of Interest}

The authors declare no conflicts of interest regarding the publication of this paper. 


\section{References}

Cao, J., Zhang, Y. J., \& Hu, W. X. (2005). Developing Characteristics of kaolInite in Central Junggar Basin and Their Effect on the Reservoir Quality. Acta Mineralogica Sinica, 25, 367-373.

He, D. F., Yin, C., \& Du, S. K. (2004). Characteristics of Structural Segmentation of Foreland Thrust Belts: A Case Study of the Fault Belts in the Northwestern Margin of Junggar Basin. Earth Science Frontiers (China University of Geosciences, Beijing), 11, 91-101.

Kuang, J., \& Qi, X. F. (2006). The Structural Characteristics and Oil-Gas Explorative Direction in Junggar Foreland Basin. Xinjiang Petroleum Geology, 27, 5-9.

Kuang, L. C., Tang, Y., \& Lei, D. W. (2014). Exploration of Fan-Controlled Large-Area Lithologic Oil Reservoirs of Triassic Baikouquan Formation in Slope Zone of Mahu Depression in Junggar Basin. China Petroleum Exploration, 19, 14-23.

Lei, D. W., Abulimiti, Tang, Y., et al. (2014). Controlling Factors and Occurrence Prediction of High Oil-Gas Production Zones in Lower Triassic Baikouquan Formation of Mahu Sag in Junggar Basin. Xinjiang Petroleum Geology, 35, 495-499.

Liu, Y. P., Wen, H. G., \& Huang, J. L. (2016). Characteristics of Authigenic Chlorite of Toutunhe Formation in the Northern Region of Fubei, Junggar Basin, China. Journal of Chengdu University of Technology (Science \& Technology Edition), 43, 487-496.

Qu, J. H., Guo, W. J., \& You, X. C. (2015). Characteristics of Xiazijieslope Breaks in Mahu Sag and Control Effect on Sand Bodies. Xinjiang Petroleum Geology, 36, 127-133.

Tan, K. J., Wang, G. D., \& Luo H.F., (2014). Reservoir Characteristics and Controlling Factors of the Triassic Baikouquan Formation in Mahu Slope Area, Junggar Basin. Lithologic Reservoirs, 26, 83-88.

Tang, Y., Xu, Y., \& Qu, J. H. (2014). Fan-Delta Group Characteristics and Its Distribution of the Triassic Baikouquan Reservoirs in Mahusag of Junggar Basin. Xinjiang Petroleum Geology, 35, 628-635.

Yu, X. H., Qu, J. H., \& Tan, C. P. (2014). Conglomerate Lithofacies and Origin Models of Fan Deltas of Baikouquan Formation in Mahu Sag, Junggar Basin. Xinjiang Petroleum Geology, 35, 619-627.

Zhang, S. C., Zou, N. N., \& Shi, J. (2015a). Depositional Model of the Triassic Baikouquan Formation in Mahu Area Junggar Basin. Oil \& Gas Geology, 36, 640-650.

Zhang, Y. W., Zeng, J. H., \& Qu, Z. Y. (2015b). Development Characteristics and Genetic Mechanism of Authigenic Kaolinite in Sandstone Reservoirs of the Dongying Sag, Bohai Bay Basin. Oil \& Gas Geology, 36, 73-79.

Zhi, D. M. (2016). Discovery and Hydrocarbon Accumulation Mechanism of Quasi Continuous High Efficiency Reservoirs of Baikouquan Formation in Mahu Sag, Junggar Basin. Xinjiang Petroleum Geology, 37, 373-382. 